Accepted (peer-reviewed) version of article

It is authorized for self-archiving after an embargo period of 24 months.

Formatted by the author to enhance readability. 


\title{
The role of materiality in numerical cognition
}

\author{
Karenleigh A. Overmann ${ }^{1}$
}

\begin{abstract}
Numerical elaboration and the extension of numbers to non-tangible domains such as time have been linked to cultural complexity in several studies. However, the reasons for this phenomenon remain insufficiently explored. In the present analysis, Material Engagement Theory, an emerging perspective in cognitive archaeology, provides a new perspective from which to reinterpret the cultural nexus in which quantification develops. These insights are then applied to representative Neolithic, Upper Palaeolithic, and Middle Stone Age artifacts used for quantification: clay tokens from Neolithic Mesopotamia, notched tallies from the European Upper Palaeolithic, hand stencils with possible finger-counting patterns as documented at Cosquer and Gargas, and stringed beads from Blombos Cave in South Africa.
\end{abstract}

\section{Introduction}

In 2011, Hayden \& Villeneuve published an article that compared the astronomy practices of contemporary societies with artifacts and cave paintings thought to reflect possible practices of astronomy in the Upper Palaeolithic. I study numerical cognition, so my immediate reaction to their article was to ask, 'How many numbers do you need to do astronomy?' The answer turned out to be 'very few', since societies with limited counting sequences practiced astronomy nonetheless. However, one of the main reasons extant peoples practice astronomy is to tell time, and the availability of numbers changes how timekeeping is practiced. Before a system of numbers develops, time is estimated from natural phenomena. People use the height of the sun for the approximate time of day, the first occurrence of particular stars on the horizon for the approximate month, the temperature trend and other seasonal changes for the approximate time of year, and so on. But once numbers are available, time becomes quantified through practices like counting lunar appearances, and timekeeping by the quantification of time tends to displace the previous estimation techniques. Compare the number of people in any particular industrialized society, for example, who know how to estimate the month by the rising stars to the number of those who know how to obtain the information from some form of calendar. Likely the former will be negligible, the latter close to the number of those in the population, minus of course the infants and children too young to have learned their calendars.

The variables of cultural complexity, number system elaboration, and quantified timekeeping are predictably related, as demonstrated by two studies showing correlations between complexity in culture, complexity in number systems, and timekeeping behavior (Overmann, 2013a,b; a two-part 1999 study by Divale similarly demonstrated correspondence between cultural complexity_assessed through indicators of food resource management strategies, such as storing grain for subsequent years-and number systems complexity). That is, timekeeping by quantification is made possible by the availability of numbers, which in turn develop greater complexity in response to cultural factors. This nexus of cultural complexity, number system elaboration, and the quantification of time suggests that an artifact used for timekeeping tells us something about the society that made it, not only things like the sedentism needed to make longterm celestial observations and the division of labor supporting the development and dedication

\footnotetext{
${ }^{1}$ Correspondence concerning this article may be addressed to karenleigh.overmann@keble.oxon.org.
} 
of specialization to collecting celestial information, but also their number system. That is, the quantification of time is associated with counting to higher numbers, which in turn are associated with the use of material technologies for counting.

For example, consider the artifact from Abri Blanchard, which the experimental recreation of ancient astronomical techniques suggests recorded the lunar analemma, the closed curve made by the moon's nightly maximum height, and lunar phases, the waxing, full, and waning shapes (Marshack, 1991; Jègues-Wolkiewiez, 2005; also see Figures 1a,b). Such detailed, materially based timekeeping is arguably distinct from the behaviors seen when time is initially quantified, which tend to consist of things like counting lunar appearances with tally marks or knots in strings (technologies that themselves tend to be associated with more extensive counting sequences), and thus it suggests the society making the artifact would have had both complex culture and complex numbers.

If the elaboration of numerical systems and the extension of numbers to non-tangible domains such as time are linked to cultural complexity, the reasons for this phenomenon remain insufficiently explored. In the present analysis, Material Engagement Theory (Malafouris, 2013), an emerging perspective in cognitive archaeology, provides a new viewpoint from which to interpret the cultural nexus in which quantification and timekeeping develop and examine the role of materiality in numerical cognition. The insights from Material Engagement Theory are then applied to representative artifacts for quantification that have been dated to the Neolithic (Mesopotamian clay tokens and ancillary technologies), Upper Palaeolithic (notched tallies and hand stencils from Europe), and Middle Stone Age (stringed beads from Africa, the Levant, and the Near East) to suggest that, if they do not represent the practice of quantification, they nonetheless represent opportunities for the development of numerical thinking.

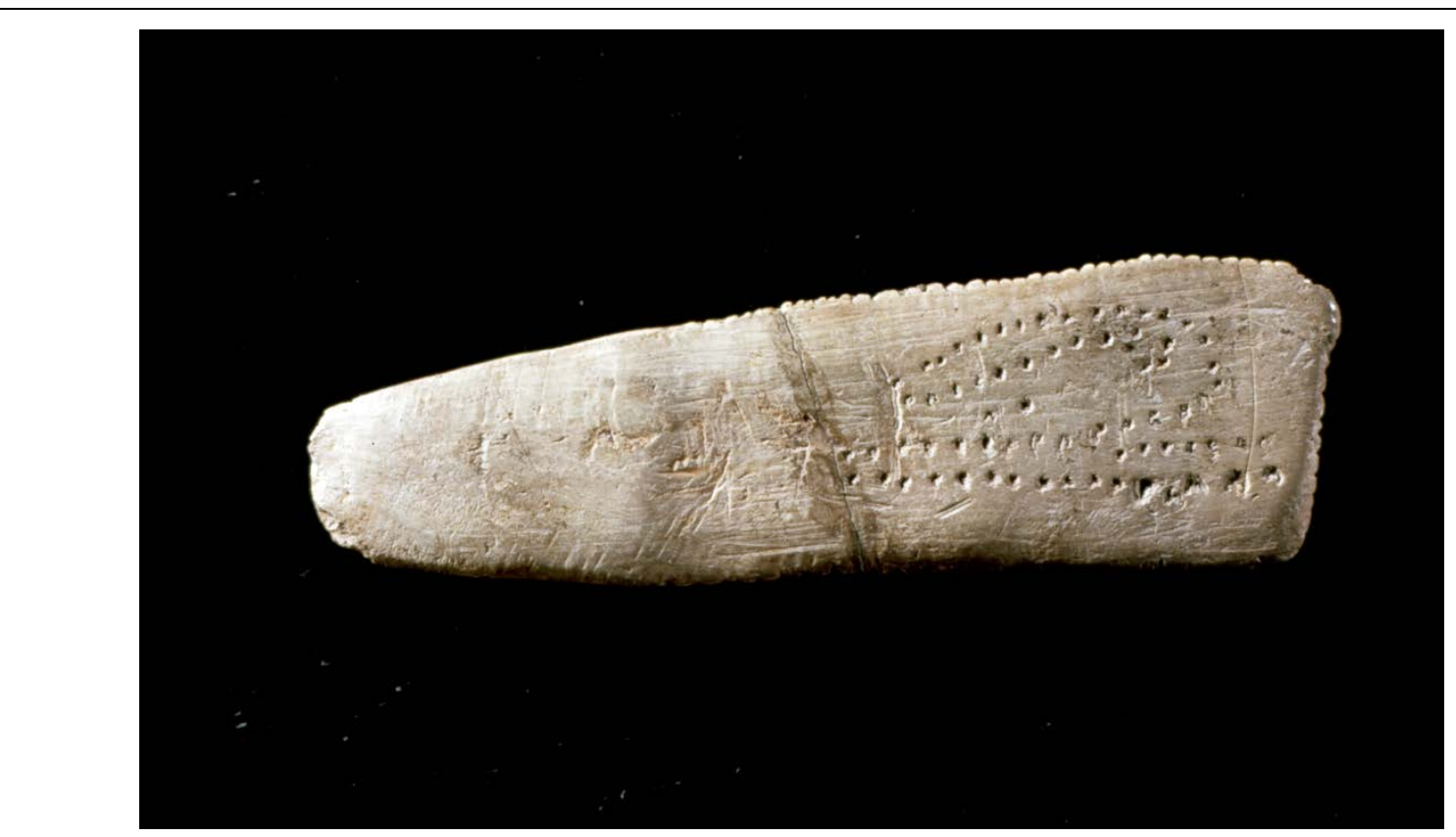

Figure 1a. Abri Blanchard artefact, c. 28 KYA. The impressions may represent the lunar analemma and phases (Jègues-Wolkiewiez, 2005; Marshack, 1991). Source: Gift of Elaine F. Marshack. Courtesy of the Peabody Museum of Archaeology and Ethnology, Harvard University, PM\# 2005.16.2.318.38 (digital file\# 98520110). 


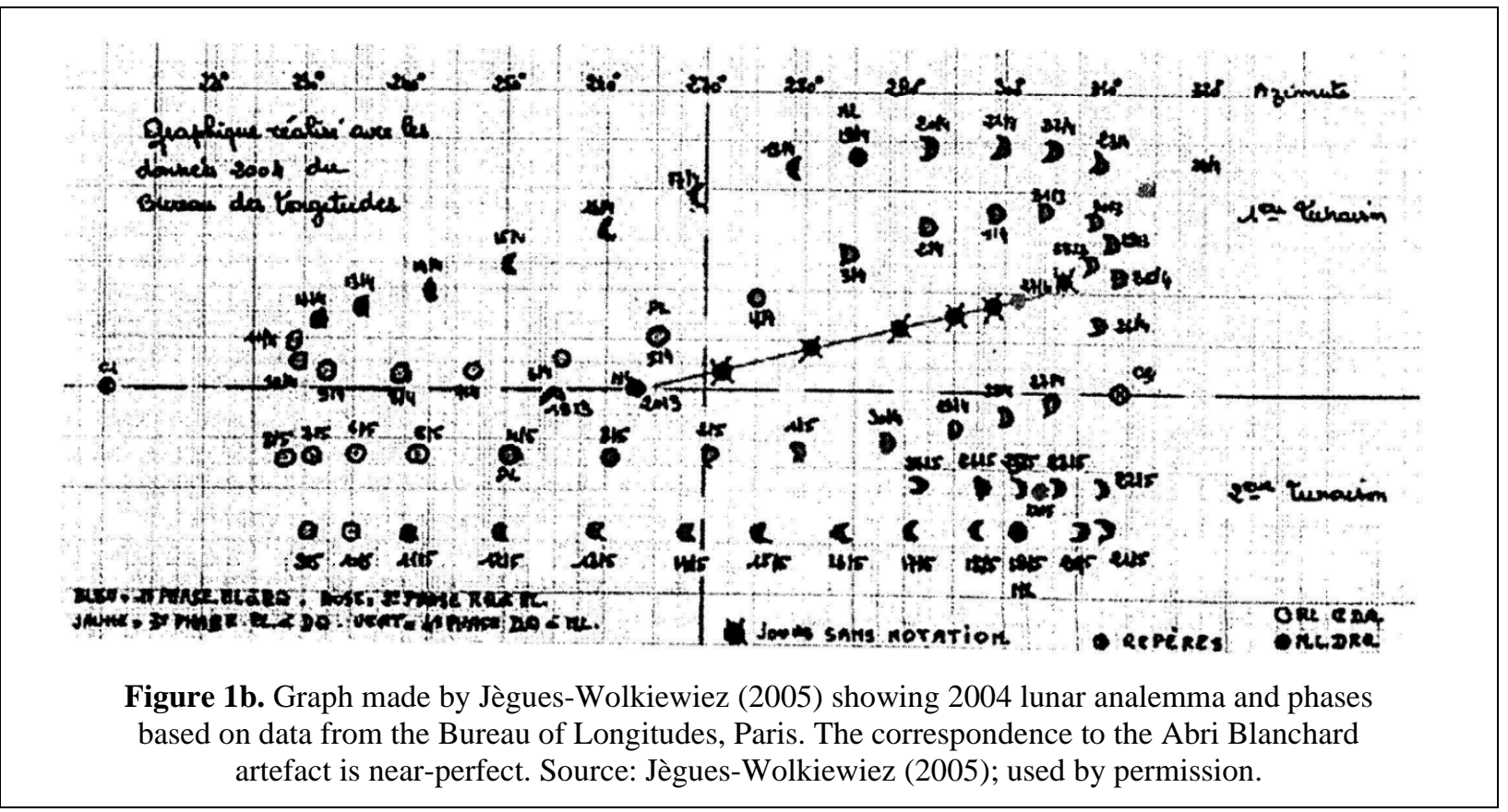

\section{The Relations between Complexity Variables}

Two studies from 2013 demonstrated links between complexity in culture and number systems. In the first (Overmann, 2013a), the variable for cultural complexity consisted of Hayden \& Villeneuve's (2011) dichotomous characterization of culture in a sample of 33 traditional societies as 'simple' or 'complex.' A measure of numerical system complexity, also dichotomous, was derived from highest number counted as described in the ethnographic literature contained in Yale University's electronic Human Resource Area Files (eHRAF; see Biesele et al., 2013). Highest number counted is a frequent measure of number system elaboration because the greater availability of numbers correlates with the likelihood that numerical relationships will be discovered; this is simply a function of increased exemplar availability (in other words, the more numbers you have, the more likely you are to notice the patterns among them; Beller \& Bender, 2011).

The results of the first study were as follows: 'Simple' numbers were associated with both 'simple' and 'complex' culture, while 'complex' numbers were associated only with 'complex' culture. Further, there were no societies with 'simple' culture but 'complex' numbers. This distribution suggested that the development of 'complex' numbers was associated with cultural complexity. Moreover, the pattern ('complex' numbers associated only with 'complex' cultures, 'simple' numbers associated with both 'simple' and 'complex' cultures) implied that material culture increased in complexity first, and number concepts were elaborated subsequently. That is, there was something about cultural complexity that appeared to motivate and enable the elaboration of numbers. Chrisomalis (1996) suggested that there was an increased likelihood of invention if the availability of antecedent resources with which to work was more extensive. This seems reasonable: Inventors necessarily draw upon the antecedent resources available to them; thus, the more complex the culture, the more antecedent resources are likely to be available.

The positive correlation between cultural and number system complexity is consistent with observations such as those made by Hayden (2001) in his work on feasting: Cross-culturally, 
societies accumulate and consume surplus in public rituals to enhance things like social cohesiveness, to build and maintain alliances, to display wealth or social power, and so on; as feasting (a proxy for cultural complexity) becomes more elaborate, the need for accounting emerges, motivating the development of methods and materials for accounting, including counting technologies and numerical notations. Thus, there is a seemingly universal tendency for humans to accumulate surplus and discharge it in public rituals; this is accompanied by another seeming universal tendency for numbers (and when things get complex enough, numerical notations and writing, which have long been associated with large state-level societies with extensive bureaucracies) to develop in reaction to complexity as a means of managing it.

The second study (Overmann, 2013b) used an expanded sample (50 traditional societies) and new sources of data, including the Standard Cross-Cultural Sample (SCCS) from the University of California at Irvine as the source of the cultural complexity index. The statistical analyses, which were more extensive than those of the previous study, examined correlation strengths between variables, assessed the reliability and consistency of data coding, and controlled for non-independent observations. The latter is the so-called Galton's problem, which is an issue in cross-cultural research because things like common descent and diffusion influence cultural traits toward similarity and relates them in a way that makes them non-independent (Chick, 1997; Denton, 2004; Murdock \& Provost, 1973). In this study, cultural complexity, a variable from the SCCS, was an index of ten summed measures of areas like social organization, technology, resourcing strategies, and so on. The index based on multiple measures was selected to mitigate the potential for the artificially higher or lower scores associated with single-domain measures (e.g., technology), recognizing that there are societies with relatively simple technology and highly complex social organization (e.g., kinship). Highest number counted was compiled from both databases and the study by Divale (1999). The ordinal categories used for highest number counted were adapted from Divale's analysis, which had similarly established correlations between highest number counted and cultural complexity as measured by food storage and other resource management practices. As was the case with the first study, increases in cultural complexity correlated with increases in highest number counted and the use of material devices for quantification. In addition, increases in cultural complexity were similarly found to have preceded increases in highest number counted, and there were no societies with 'simple' culture but 'complex' numbers.

The results of the two studies demonstrated that as culture became more complex, the use of material devices for counting and highest number counted increased. The idea that there would be a relation between the availability of counting devices and highest number counted seems intuitive: Artifacts for counting seem like just the thing to help us count to higher numbers. The availability of numbers also changed timekeeping behavior: Time became quantified, displacing the previous use of natural associations, and increasing the likelihood of counting human age, dividing time in ways that were quantificationally structured, and improving the accuracy and precision of astronomical measuring (e.g., using solstices and equinoxes; adjusting for the mismatch between the solar and lunar cycles). This effect too is commonsensical: When numbers are available, they are used and applied to many domains, and by their nature, they tend to structure those domains in terms of quantity; thus, when numbers are applied to time, time becomes quantificationally structured.

Some behaviors, however, did not change: Finger-counting, which has neurological and physical bases for its cross-cultural prevalence and similarities in things like starting with outside fingers and moving across the hand (Andres, di Luca, \& Pesenti, 2008; Bender \& Beller, 2011, 
2012; Overmann, 2014), remained practiced regardless of whether the number system was elaborated or not. Telling myths about celestial phenomena, which may support aspects of social identity (Ochs \& Capps, 2001), did not decrease as number systems became more elaborated. Finally, resourcing remained based on the natural seasons, probably for pragmatic reasons (that is, because it is more effective to hunt and gather or sow and reap according to the temperature trend and other seasonal indicators than the calendar, which is in a sense divorced from actual conditions; Hayden \& Villeneuve, 2011).

Overmann (2013a,b) explained the relation between cultural complexity and numerical elaboration as things to count causing reasons to count them, based on ethnographic descriptions associating the absence of counting with a lack of material possessions and noted that when it came to counting, material possessions were not created equal. That is, some acquired social value because of the scarcity of the material used to make them or the investment of labor needed to produce them, and objects with value characteristics were correspondingly more likely to be counted. However, this explanation did not seem to answer fully the question of why material complexity would precede and inform numerical elaboration. Understanding this phenomenon requires insights from Material Engagement Theory.

\section{Material Engagement Theory and the Role of Materiality in Numerical Cognition}

Material Engagement Theory (Malafouris, 2013) is a new perspective in cognitive archaeology on the role that material culture has in human cognition - even a new definition of what cognition is, as not just something the brain does, but a complex system that includes brains, bodies, and materiality, including material culture. This view bridges the Cartesian distinction between mind and matter to suggest that not only is cognition more than just the brain or the brain and the body, it also includes materiality as a constitutive component, as well as a catalyst. The historic view of material culture as something we make, a byproduct of the encephalized, intelligent human brain that uses tools to accomplish its goals, is reframed to say that our unique adaptation as a species is incorporating material culture as an integral part of our cognitive system. Engagement with materiality is also seen as providing opportunities for existing brain functions to be applied to new cultural purposes, or for the brain to develop new functions or regions. Simply, it is not the mind that makes the tool, but the tool that makes the mind, or rather, they co-create each other (Malafouris, 2013).

Materiality's role in our cognition is often underappreciated. For example, we notice that cross-culturally, the first arithmetic operation to emerge in numerical cognition is typically addition, but we seldom notice that accumulation is implicit in behaviors like pairing that help realize our initial number concepts, or that accumulation is something that early counting technologies have in common (subtraction is much less common, possibly because early counting technologies do not support it as readily, as erasing notches on a tally stick is not as easily accomplished as accumulating them). Believing that the emergence of addition has nothing to do with the use of accumulative behaviors and material devices would fail to exploit an opportunity to investigate the role that materiality plays within numerical cognition. An alternative view suggested by Material Engagement Theory would be that the emergence of addition is likely a function of the materiality we use, how we interact with it, and how its properties interact with our psychological and physical capabilities.

Viewing cognition as a complex system that includes materiality allows us to examine the 
role of materiality within the system. Artifacts help us decompose problems into smaller tasks, which are more easily solved because they are smaller and because multiple individuals can collaborate in problem-solving. Solutions in the form of artifacts distribute cognitive effort over space and time (Hutchins, 1995). A calculator, for example, represents a wealth of past invention and knowledge, available to anyone who uses it. Prehistorically, our ancestors were not using electronic calculators, but they were using things like fingers and notched bones. These enabled them to invent new concepts and devices, which they taught to others, who refined, extended, standardized, and codified them in material artifacts and language. Our calculators reflect much of that previous effort, as well as the history of invention reflected by the numerical notations, the materials like plastic used to make the artifact, the software that implements the algorithms, and so on.

Materiality both represents and influences social needs and priorities, as for example the need to account for feast goods or stored food resources (Divale, 1999; Hayden, 2001; SchmandtBesserat, 2001). Artifacts that are scarce or rare, or which represent prestige or significant investments of labor, not only give rise to systems of value but the need for enumeration (Overmann, 2013a,b). As societies incorporate material culture, their lifestyle begins to depend on it, so they invest new energy in maintaining, sustaining, and expanding the materiality that is socially vital — a process of entanglement that changes and intensifies behavior, especially over the long term (Hodder, 2012). The long-term interaction between brains, bodies, and materiality is what allows them to influence and change one another. Over long spans of time, interaction with materiality can repurpose existing brain functions for cultural algorithms, as for example the repurposing of the innate sense of quantity for the ability to understand and reason with discrete non-symbolic quantities and numerical symbols (Dehaene, 2007) or object recognition processes being co-opted for word recognition in reading. In addition, new brain functions and regions can emerge, as appears to have been the case with the human intraparietal sulcus, which contains regions specialized for representing dimensional aspects of shape that have no homology in monkeys, suggesting they are evolutionarily new (Orban et al., 2006; Dehaene \& Cohen, 2007).

Potential outcomes are enabled or constrained by what materiality is capable of, in posing problems and potential solutions. In numbers, different counting technologies shape numerical cognition through their properties (which Gibson, 1977, 1979 called affordances). For example, fingers are available in a way that strings of beads are not, since fingers are a typical anatomic feature whose neural control interacts with the perceptual system for quantity. Beads, by comparison, must be manufactured, and then reapplied from ornamentation to counting. Yet finger-counting is generally limited to low numbers (toes are often recruited to extend the fingers' limited capacity), while strings of beads need not be (for example, the North American Pomo were described as using strings of beads to count into tens of thousands; see Barrett, 1952). It is fairly easy to put notches onto a stick, but once they are there, taking them off is difficult. This problem does not occur with knots in strings, since knots can be untied or are fairly easily cut off the end of the string. Artifacts like tokens afford, in addition to the accumulation potential of the tally and the subtraction potential of the string, a degree of manipulability not found in either of the other counting technologies (that is, it is possible to rearrange the elements into various quantity combinations without needing to alter or destroy the material of which the technology is made). Tallies with notches and strings of knots, however, persist in the quantities they instantiate in a way that loose tokens do not, unless they are somehow contained (think of what happens to the quantity instantiated when each form of counting technology is dropped on the ground, for example: Tokens would scatter and possibly break, while the others would not). 
The interaction between brains, bodies, and materiality changes the cognitive system for numbers: As the cognitive system involves materiality, the innate sense of quantity appreciation known as numerosity, which is shared by many species, is externalized, made tangible, and given structure, stability, and manipulability, characteristics that reflect a numerical elaboration unique, so far as we know, to Homo sapiens (Malafouris, 2010; Coolidge \& Overmann, 2012). The sense of quantity becomes explicit, discrete, and persistent, affording opportunities to notice similarities and patterns. These, in turn, enable categorization and abstraction, increasing the likelihood that concepts will be codified and endure in the form of language and culture, including material artifacts. While both language and artifacts provide a mechanism for distributing knowledge over space and time, it is the latter in particular that distributes cognitive effort temporally and geographically. Any material technology for manipulating quantity instantiates "knowledge that would be exceedingly difficult to represent mentally” (Hutchins, 1995, p. 96).

An abacus, for example, represents numerical knowledge - things like discrete quantities, relations between them, place value, and so on - that was discovered, codified, and extended by previous individuals, over a span of decades if not centuries, and its structure was designed to automate the numerical algorithms it was built to perform, making the numerical algorithms an implicit feature of the abacus design. Of course, this is not to affirm that the numerical knowledge and algorithms were worked out first and the abacus built to reflect them: Likely the numerical knowledge and algorithms were realized gradually by interacting with earlier versions of the materiality used to support quantification (i.e., earlier abaci designs and other counting technologies). When we use a device like an abacus, we do not need to know or even understand all the things that went into its design; we merely need to know how to use it to perform whatever task is at hand.

The use of the brain changes as materiality is incorporated: There are decreases in the reliance on spatial heuristics and the demands on working memory, freeing up cognitive capacity for other purposes, such as noticing the similarities and patterns that engage the psychological processes of categorization and abstraction. From the initial involvement of the parietal lobe, there is greater recruitment of the frontal lobe and its executive functions, affording opportunities for intentionality and goal-directed behavior. The characteristics of the number system change as well: As materiality is incorporated, highest number counted increases, which in turn increases the likelihood that the relations between numbers will be discovered. Numbers begin to act as a cognitive technology, structuring the way the world is understood (de Cruz, 2008, 2012). The utility of numbers, in interaction with social needs, increases the likelihood that numbers will be extended to new domains, including intangible ones, like time.

\section{A Material Engagement Theory Perspective on Quantification Artifacts}

Several short-term effects of incorporating materiality into the cognitive system have already been mentioned. Such artifacts minimally show material engagement, task decomposition, distributed cognitive effort, motor activity, opportunities for learning, the acquisition of skill, change in psychological processing, and the redesign and extension of the artifacts themselves.

As was also mentioned, key long-term effects include the repurposing of existing brain functions for cultural functions, and allowing new brain functions or structures to emerge. The engagement of materiality not only influences the functionality of the brain in way that is inheritable rather than Lamarckian, it can influence humanity's genetic future as well. Various mechanisms for the co-evolution of culture and genes have been proposed, including the idea that 
alteration of the environment changes selective forces (Kendal, Tehrani, \& Odling-Smee, 2011); the ratchet effect, which constrains possible actions to influence potential outcomes (Tomasello \& Herrmann, 2010; Tomasello, Kruger, \& Ratner, 2010); genetic assimilation, in which phenotype selection becomes genetically encoded (Hall, 2003; Waddington, 1942); and the Baldwin effect, in which sustained, learned behaviors influence survival (Baldwin, 1896a,b; Depew, 2003). A more detailed review of these effects is contained in Wynn and colleagues (2017), which discusses how the ability to appreciate ordinal sequences, which are cultural rather than natural, might arise through the confluence of material engagement and selective force.

Ways in which representative prehistoric counting technologies-Neolithic clay tokens and related materials such as clay bullae, envelopes, and tablets; Upper Palaeolithic notched tallies and hand stencils in cave art, and Middle Stone Age stringed beads-may have functioned within the cognitive system for numbers to provide opportunities for short- and long-term effects to emerge are reviewed in the remainder of the present article.

\subsection{Clay Tokens.}

These artifacts were used in the Ancient Near East between the eighth and first millennia (SchmandtBesserat, 1992a; MacGinnis, Monroe, Wicke, \& Matney, 2014). Their most common shapescones, spheres, discs, cylinders, and tetrahedrons - are roughly consistent with, though not identical to, those of the first proto-writing for numbers (Schmandt-Besserat, 1992a; see Figure 2). They occur similarly in two sizes (larger and smaller), suggesting that tokens may have been used as a means of counting and manipulating quantity, with numerical notations recording the results of calculations (Nissen, Damerow, \& Englund, 1993; Glassner, 2000). As a counting technology, their story is of technological innovation distributed over space and time, as the tokens were impressed into clay envelopes, a process thought to have informed the invention of both numerical notations and writing (Schmandt-Besserat, 1992b; but also see Glassner, 2000, who suggests that writing primarily developed from pictographs and ideographs). This process of technology change required hundreds of years, involved many individuals, and spread throughout the region, illustrating Hutchins' (1995) idea that materiality distributes cognitive effort over space and time.

If the clay tokens are included with cuneiform writing and technologies like the bullae, envelopes, and tablets thought to be intermediate between the clay tokens and numerical notations, the tokens and ancillary technologies represent the material components of a particular form of numerical cognition that persisted for thousands of years, and which continues to inform some of our numerical thinking today. For example, the 60 -minute hour is often described as having been influenced by the Mesopotamian sexagesimal or base 60 numbering system. While modern timekeeping divisions of hours and minutes "bear no direct relation with Sumerian tradition," the former appear to have been based on the latter by medieval clockmakers who knew and admired the sexagesimal system used in Babylonian astronomy (Englund, 1988, pp. 121-122). The distribution of cognitive effort does not entail that previous inventions are merely carried forward into the future, unchanged, though it also does not preclude this as a possibility; rather, they become part of the available antecedents out of which inventions are built or inspired (Chrisomalis, 1996).

The Mesopotamians also bundled their numerical notations, a procedure in which six, ten, or three signs equated to one sign of a different size or shape, and it is possible that the precursor tokens were endowed with similar meanings. By the late fourth millennium, the Mesopotamians also quantified time in amounts we easily recognize-30-day months, 12-month years-and by 
the third millennium BC were adjusting for the mismatch between solar and lunar cycles (Englund, 1988). When the predictive relations between numbers and time are considered, characteristics such as these suggest that the tokens represented a number system that was relatively mature even by the late fourth millennium. Such maturity would be consistent with cultural complexity, which the Mesopotamians also certainly had in abundance by the late fourth millennium. In view of the predictive relations between cultural complexity, quantification technologies, timekeeping behavior, and highest number counted, the Sumerians and Akkadians would have had lexical numbers well before number signs appeared in the late fourth-millennium in the form of protocuneiform impressions (Glassner, 2000). It seems reasonable to suggest that the Mesopotamian peoples would have developed number words after counting on their fingers and with naturally occurring objects first, as extant peoples are documented as doing, before they would have been motivated to make counting artifacts from clay.

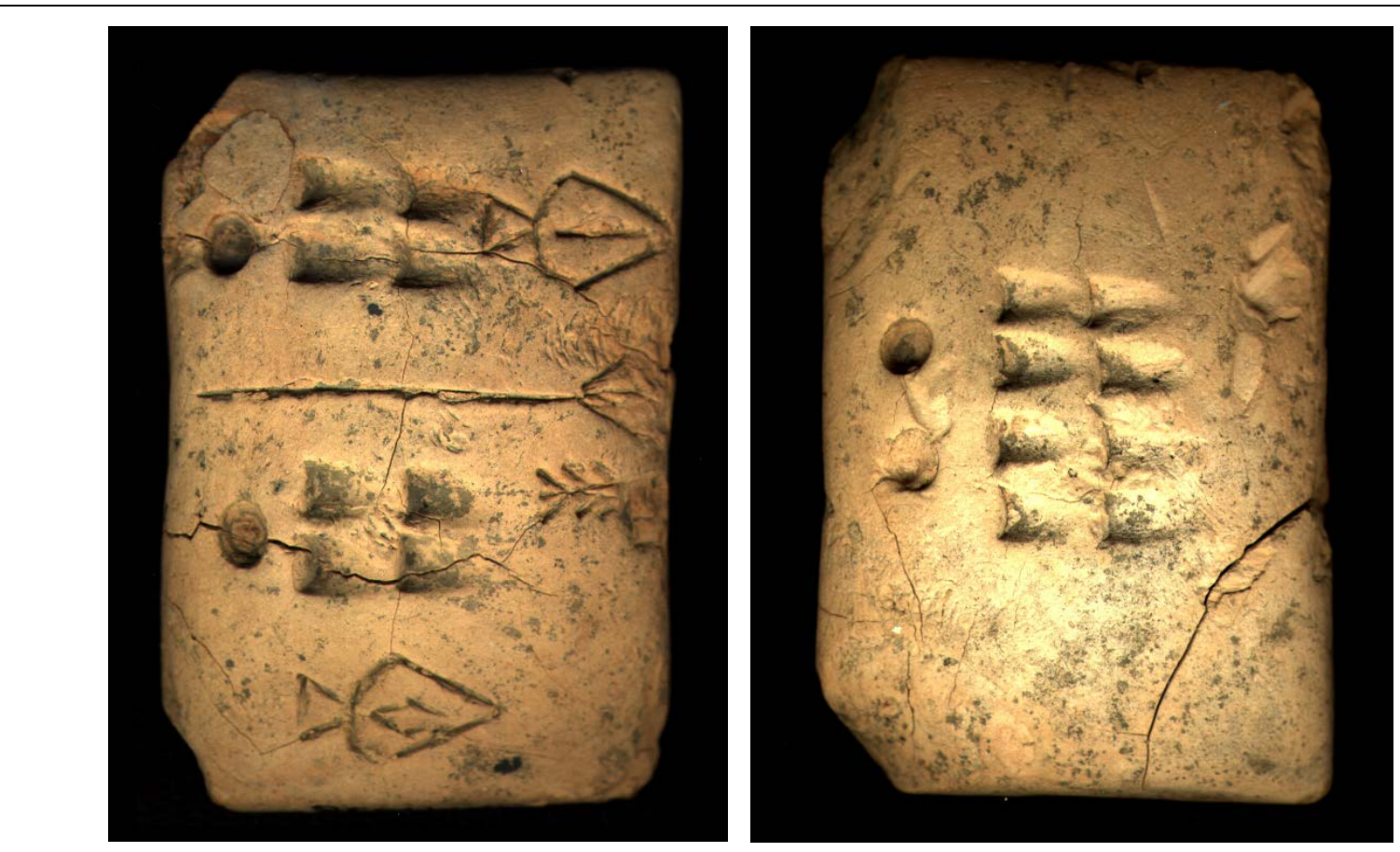

Figure 2. Proto-cuneiform tablet (W 9578,g) from Uruk IV, 3350-3200 BC, with numerical impressions and commodity inscriptions. Left: Obverse side of tablet. Both columns (read left to right) contain a single ten-unit (circular impression), four one-units (conical impressions), and incised signs indicating the commodity being enumerated. Right: Reverse side of tablet. The value (two ten-units and eight one-units) sum the columns on the obverse side. Source: Vorderasiatisches Museum, Berlin.

\subsection{Notched Tallies.}

Notched bones are found throughout the Upper Palaeolithic; two well-known examples from France are shown in Figures 3a,b: the plaque from the Grotte du Taï (c. 14,000 years ago [KYA]) and artifacts from Abri Cellier (c. $28 \mathrm{KYA}$ ). Their use for quantification is ambiguous, probably more so in the case of the Abri Cellier bones, since it is also possible that the cutmarks were meant to be decorative. Historically, archaeologists have tried to differentiate decoration from 
quantification by analyzing cutmarks; those made at-a-time are probably decorative, those made over time more likely to be quantificational (d'Errico, 1991). By no means do I advocate doing away with these traditional methods of understanding the purpose of such artifacts; however, I do suggest that we supplement them with insights gained from Material Engagement Theory.

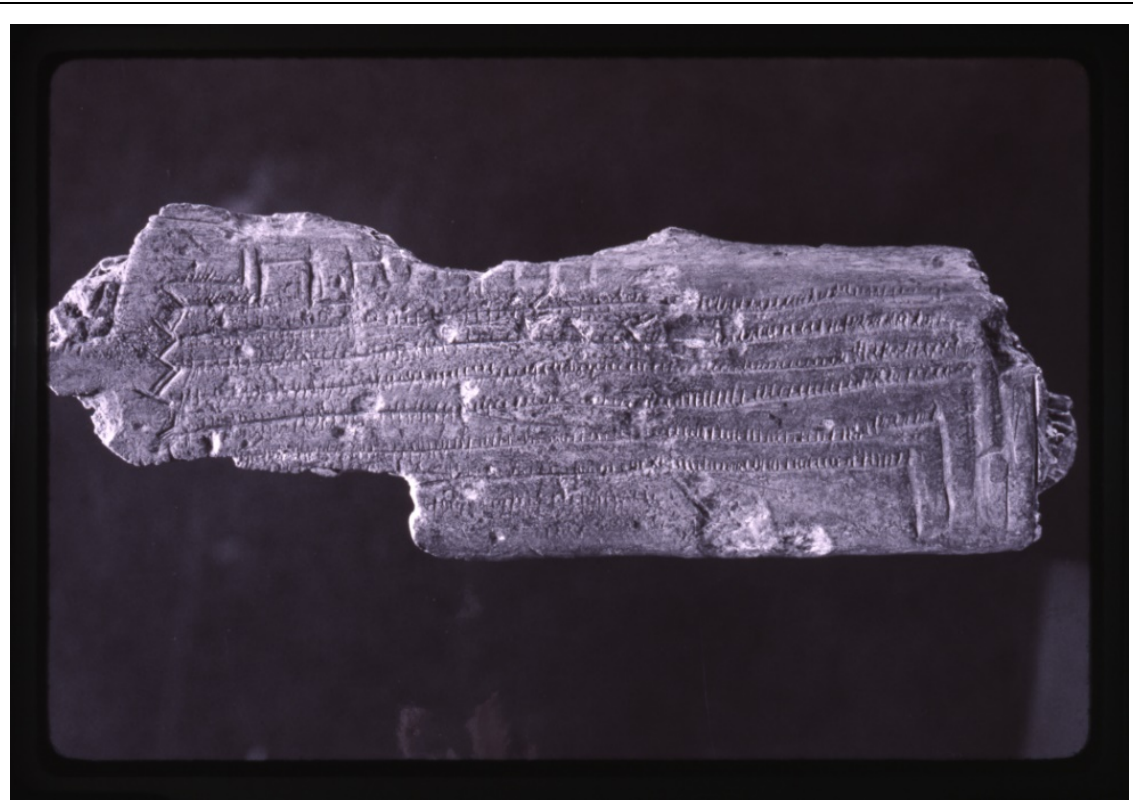

Figure 3a. Plaque from Grotte du Taï, c. 14 KYA. The marks may represent quantification (Coolidge \& Overmann, 2012; Marshack, 1991). Source: Gift of Elaine F. Marshack. Courtesy of the Peabody Museum of Archaeology and Ethnology, PM\# 2005.16.2.59.75 (digital file\# 99210130).

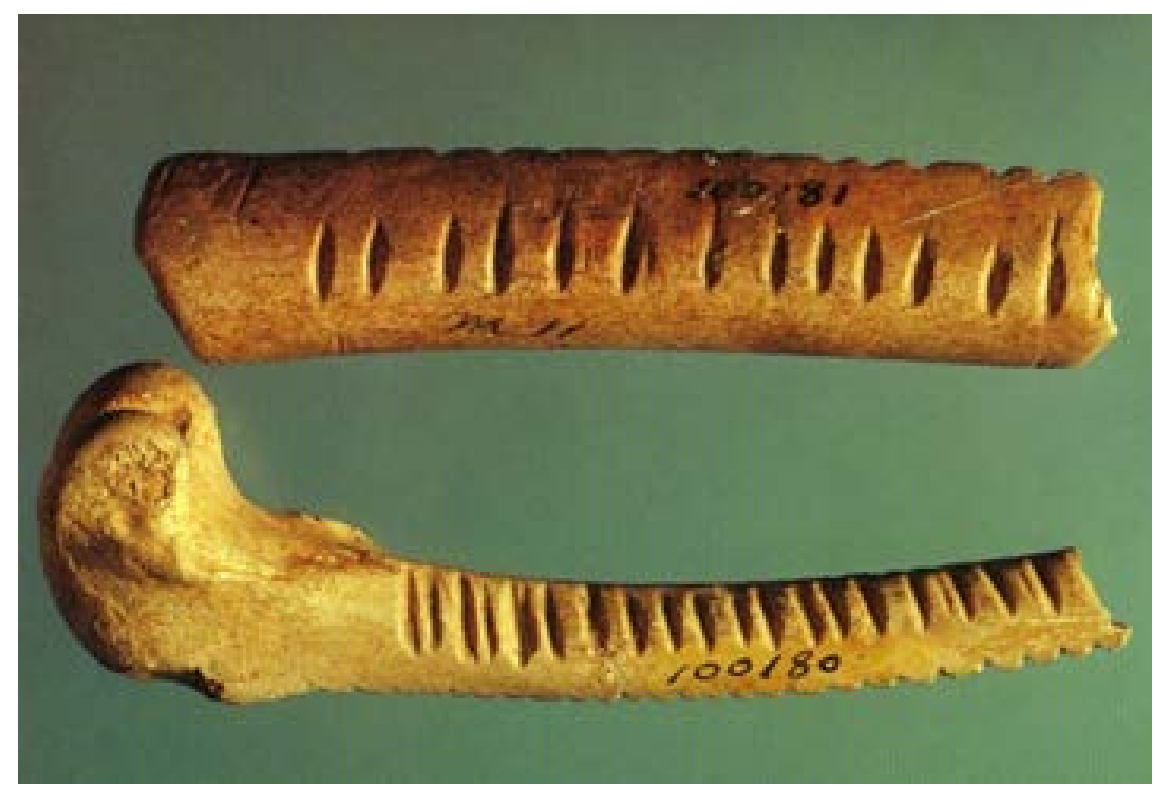

Figure 3b. Notched bones from Abri Cellier, c. 28 KYA. The cutmarks might have represented quantification (Coolidge \& Overmann, 2012) but could also have been decorative in intent (d'Errico, 1991). Source: Logan Museum of Anthropology, Beloit College (LMA 100180 and 100181). 
I said earlier that cultural complexity preceded and likely informed the development of numbers, and that social values and interactions provided things like motivation, cooperation, learning, and the availability of antecedent resources. Most importantly, from a Material Engagement Theory perspective, material engagement provides opportunities that can enable number concepts to be realized. A notch on a bone, even if it were originally made for the purpose of decoration, also provides a discrete quantity that can be used as an external referent. Thus, the tally instantiates a discrete quantity that can indicate quantity without or with language for numbers (the distinction between 'that many' and 'how many'). Notches also provide the kind of tactile and visual regularity important in numerical patterning. That is, each additional notch bears a specific quantity relationship to the notches preceding and succeeding it. The accumulation of notches also instantiates the 'plus-one' relationship, which forms new quantities by adding one to any preceding quantity, and thereby perhaps provides a manuovisual basis for the idea of the successor function. As a motor activity, the accumulation of notches also provides opportunities for learning, practice, and the development of skill. These tactile and visual regularities represent opportunities for the application of existing psychological processes (e.g., categorization, working memory) to be applied to functions such as pattern detection and the manipulation of information; existing psychological processes can also be repurposed to new cultural algorithms (Coolidge \& Overmann, 2012) and, over time, new psychological processes can emerge (Wynn, Overmann, Coolidge, \& Janulis, 2017).

\subsection{Finger-counting.}

In the invention of numbers as viewed through ethnographic and linguistic data, fingers generally precede material devices, in a way that is explainable neurologically and which is cross-culturally similar in modern peoples (Overmann, 2014), so Upper Palaeolithic tallies imply peoples who would have also counted on their fingers as a precursor technology. Obviously, most of the time the archaeological record does not preserve the use of fingers for counting. However, there are a couple of intriguing possible exceptions at Cosquer and Gargas in France about 27 KYA (see Figure 4). In 2006, Rouillon noted that of the negative hand stencils at Cosquer, of the possible 32 permutations it is possible to make by lengthening or shortening the fingers of one hand, the stencils comprised only five - the five you would expect to form the integers 'one' through 'five' in typical finger-counting. That is, extension of only the thumb might form the integer 'one', extension of the thumb and index finger the integer 'two', extension of the thumb, index finger, and middle finger the integer 'three', and so on until all five fingers are extended to form the integer 'five'. The hand stencils at Cosquer, and five of those found at Gargas as well (LeroiGourhan, 1967), could indeed represent finger-counting: The hand stencils are consistent with characteristics of modern finger-counting systems in terms of things like the starting and ending fingers (typically the thumb or the little finger), type of finger modification (generally extended or flexed), and sequence of use (generally across the hand, including finger patterns that are difficult to make, such as extending all fingers except the little one); the hand stencils would also be consistent with the neuroscience that interrelates fingers with numerosity and the expression of numbers in material form (Overmann, 2014; also see Coolidge \& Overmann, 2012).

The recording of quantities, the purpose implied by the stenciling of finger-signs for quantity on the walls of the caves (if indeed such was the purpose), is distinct from the accumulation or manipulation of quantities (an idea that implies ancillary counting technologies such as notched tallies or knotted strings), as well as the embodied experience of quantity. There 
is perhaps a larger context of possible quantification devices, as these have been found in roughly the same geographic region and have been dated to a roughly similar time span (e.g., the notched bones from Abri Cellier), and they suggest a practice of quantification that might have included both artifacts and images. In terms of affordances, fingers and finger-stencils have less potential for accumulating higher quantities than notched bones do; stencils on cave walls are also not as transportable as artifacts would be, though they are more permanent in the sense of being less easily lost. However, notched bones, if indeed part of the same tradition that included the hand stencils, imply that quantificational marks on cave walls would have been a feasible alternative to stenciling. In turn, this suggests that the hand stencils, however quantificational their intent may have been, likely served other social purposes in addition to the recording of quantity, as their location in unlit, relatively inaccessible caves had already implied.

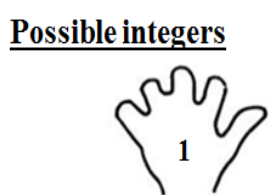

Cosquer:

Gargas:

C1: 3

$0: 33 b, 22 r$

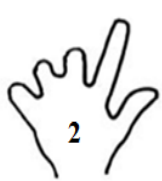

C2: 6

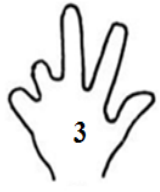

C3: 14

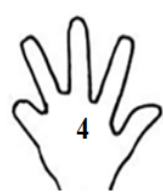

C4: 5

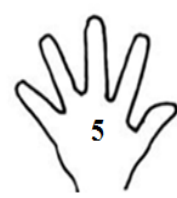

C5: 21

$\mathrm{N}: 3 b, 3 r$

H: 7b, 0r

$E: 2 b, 0 r$

A: $14 b, 3 r$

Possible non-numeric signs

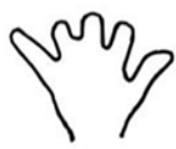

Gargas:

$\mathrm{K}: 1 \mathrm{~b}, \mathbf{4 r}$

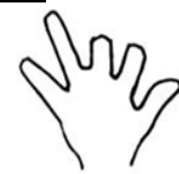

F: $0 b, 2 r$

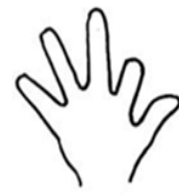

B: 3b, 0r

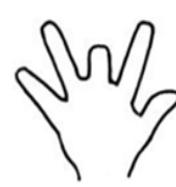

C: $12 b, 0 \mathrm{r}$

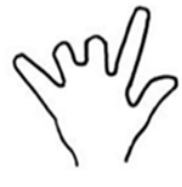

G: $1 b, 2 r$

Figure 4. Cosquer and Gargas hand stencils, c. 27 KYA. Designations (C1 through C5 for Cosquer, O through A for Gargas) were assigned by Leroi-Gourhan (1967) and Rouillon (2006). Numbers following each designation are the quantity of each stencil type; the color of the Gargas stencils is also shown (b, black; r, red). Source: Adapted from Leroi-Gourhan (1967) and Rouillon (2006). Published previously in Rock Art Research 31(1) and used by permission.

\subsection{Stringed Beads.}

Beads are prevalent in the Middle Stone Age. They have been found at some 30 sites, most famously at Blombos Cave, South Africa, which have been dated to about 75 KYA (Henshilwood, d'Errico, Vanhaeren, Van Niekerk, \& Jacobs, 2004; d'Errico, Henshilwood, Vanhaeren, \& Van Niekerk, 2005; Vanhaeren, d’Errico, Van Niekerk, Henshilwood, Erasmus, 2013; also see Figure 5), but they have also been found in northern Africa (El Greifa, El Mnasra I, Ifri n’Ammar, Grotte des Pigeons, Oued Djebbana, and Rhafas), the Levant (Es-Skhul, Ksar'Akil, and Qafzeh Cave), and the Near East (Üçağılılı Cave) as well (see Kuhn, Stiner, Reese, \& Güleç, 2001; Güleç, Kuhn, \& Stiner, 2002; d'Errico, Henshilwood, Vanhaeren, \& Van Niekerk, 2005; Vanhaeren, d'Errico, Van Niekerk, Henshilwood, Erasmus, 2006; Bouzouggar et al., 2007; Zilhão, 2007; Bednarik, 2008; d’Errico, Vanhaeren, \& Wadley, 2008; d’Errico et al., 2009; Kuhn et al., 2009; and Jerardino 
\& Marean, 2010). Many such finds from the African Middle Stone Age date to around 100 thousand years ago (McBrearty \& Brooks, 2000), and in total the finds from all sites distribute Middle Stone Age beads over roughly 6,300 km and some 40 thousand years, ample time for selection and genetic change (Wynn et al., 2017).

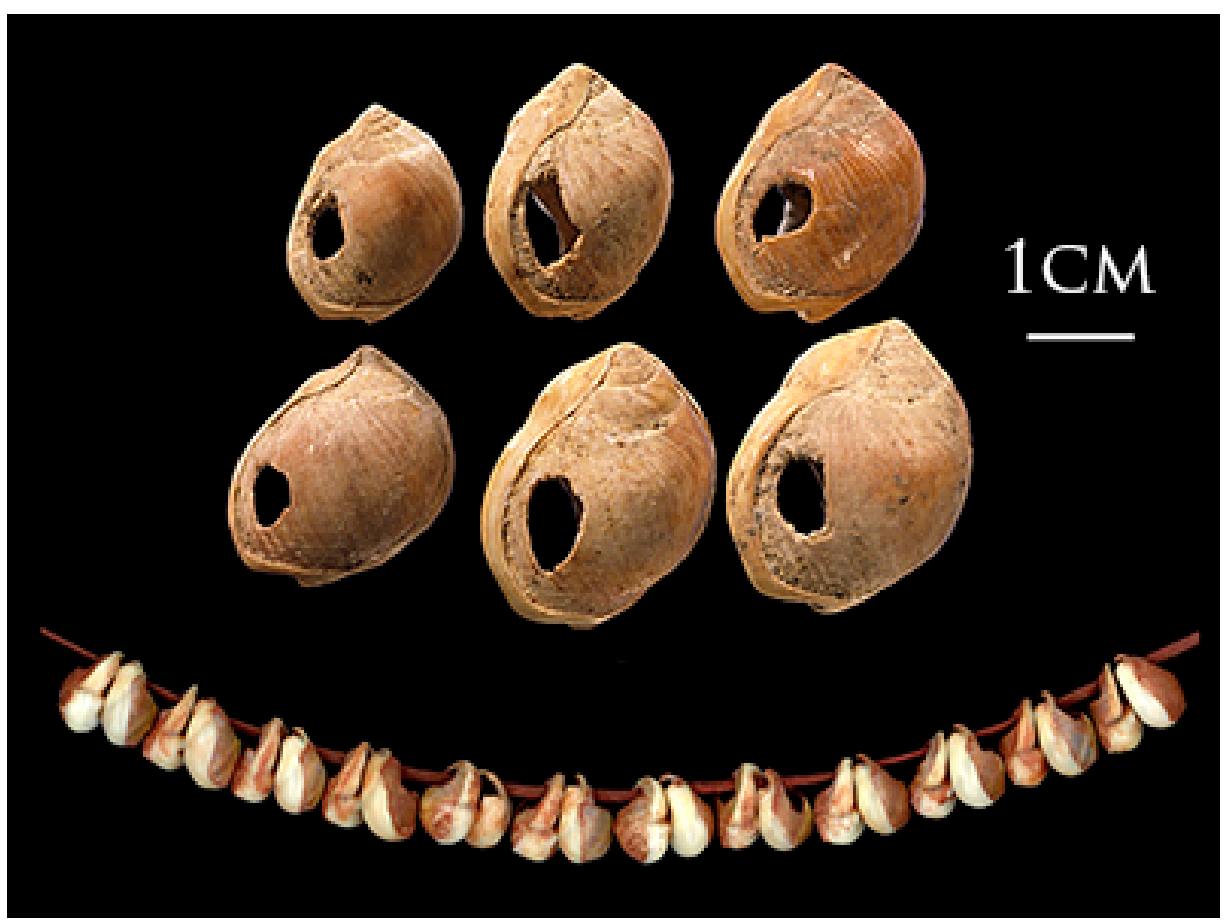

Figure 5. Six of the Nassarius kraussianus marine shell beads from Blombos Cave, South Africa, c. 75 KYA, and reconstruction of bead stringing. When strung, the beads could have been used as a counting device similar to the rosary, though their primary and most typical purpose was likely to have been personal ornamentation. Source: Marian Vanhaeren \& Christopher S. Henshilwood.

While most modern societies make and string beads, they are typically used for personal ornamentation, a form of social signaling that designates things like group affiliation, social standing, or wealth. Only a subset of the societies making and wearing beads as ornaments also use them for counting (Overmann, 2013a). The typical modern use of beads suggests that prehistoric beads would similarly have been used for personal ornamentation and social signaling as their primary purposes; any use for counting would likely have been significantly less frequent. However, even if they were made and used for ornamentation and signaling purposes, stringed beads nonetheless represent opportunities for material engagement and the realization of number concepts: They instantiate tactile and visual regularities, ordinality (each bead has a relation to the beads preceding and succeeding it), cardinality (the total number of beads), the number line (beads slid along the string), and the successor function (each bead is plus-one in quantity to the bead it follows). It takes a great deal of labor to make beads - collecting the materials, carefully punching the holes, and threading them through some kind of string. This labor-intensiveness makes it plausible that they would be valued as objects, and they designate social standing when worn, so they also imply social value and hence reasons they might have been likely to have been counted, 
perhaps even as ornaments. And, like the modern rosary, stringed beads are easily used as a counting technology, moreover one that does not require any vocabulary for or concepts of numbers to use: Each bead simply corresponds to whatever is being counted with them (as in the rosary, where each bead represents a prayer).

Notably, with the beads of the Middle Stone Age we have gone back as far as we can in the archaeological record with objects that are possibly quantificational in their intention. Here the limits of archaeology to inform us about the material component of numerical cognition become apparent, since by the time a counting technology is made of non-perishable materials, it is likely to have been preceded by the use of materials that do not preserve, like fingers and manuports and artifacts made of plants, perishable materials that are cross-culturally prevalent and extensively documented in the ethnographic literature. For this reason, the archaeological record may significantly underestimate the true time depth for counting, and hence, our numerical cognition.

\section{Conclusion}

As Malafouris (2013) has noted, the role of materiality in cognition is underappreciated in general, and in this regard numerical cognition is no exception. The reasons for the lack of appreciation include the Cartesian assumption that mind and matter are distinct substances, the transparency of the functioning of materiality and the body within cognition that seemingly locates cognition in the head, and neuroscience's methodological focus on the brain (Renfrew \& Malafouris, 2008; Tallis, 2011). Assumptions can however be questioned, transparency undone by recognizing that materiality shapes us even as we shape it (Haas, 1996), and methodology expanded in a way that allows new, enriched understandings of the phenomenon that is human cognition-as for example, considering and investigating cognition as a system that includes materiality and the body rather than focusing solely on the brain.

While the idea that our cognition depends on our material culture is not new, the discussion has been framed in terms of devices like calculators assisting and offloading our mental computations (e.g., discussions of externalized memory). Even performing computations more directly using pencil and paper or an abacus has historically tended to keep the idea of where the computations themselves are performed sequestered in the head. But the brain is hardly alone when it comes to numerical thinking, a system comprised by the interactivity of brains, bodies, and materiality - the physical structures that code and express numerical concepts, the medium that stores and allows manipulation of the physical structures by hand and eye, the algorithms that decompose tasks into manageable chunks, the distributed cognitive effort reflected by the availability and arrangement of the component parts within the system, the structuring that facilitates our apprehension as it compensates for the various limitations of psychological processes like attention and working memory. Acknowledging that there is more to numerical cognition than just the brain enables us to notice phenomena like the coincidence of artifactual accumulation and the emergence of addition, freeing us to investigate the ways that materiality influences, co-creates, and participates in our numerical thinking.

The role of materiality in numerical cognition is just beginning to be recognized, and much work remains to be done in its unpacking, investigation, and analysis. As the present review hopes at least to help make a beginning, it also suggests that materiality shapes our thinking in ways that invite us to consider it more deeply. 


\section{References}

Andres, M., di Luca, S., \& Pesenti, M. (2008). Finger counting: The missing tool? Behavioral and Brain Sciences, 31(6), 642-643.

Baldwin, J. M. (1896a). A new factor in evolution. American Naturalist, 30(354), 441-451.

Baldwin, J. M. (1896b). A new factor in evolution (continued). American Naturalist, 30(555), 536-553.

Barrett, S. A. (1952). Material aspects of Pomo culture (Vol. 20). Milwaukee: Milwaukee Public Museum.

Bednarik, R. G. (2008). Beads and cognitive evolution. Time and Mind: The Journal of Archaeology, Consciousness and Culture, 1(3), 285-318.

Bender, A., \& Beller, S. (2011). Fingers as a tool for counting: Naturally fixed or culturally flexible? Frontiers in Psychology, 2, 1-2.

Bender, A., \& Beller, S. (2012). Nature and culture of finger counting: Diversity and representational effects of an embodied cognitive tool. Cognition, 124(2), 156-182.

Biesele, M., Bleek, D. F., Jones, N. G. B., Cashdan, E. A., Denbow, J. R., Draper, P., ... Yellen, J. E. (2013). Electronic human relations area files. New Haven: Human Relations Area Files. http://hraf.yale.edu/

Bouzouggar, A., Barton, N., Vanhaeren, M., d’Errico, F., Collcutt, S., Higham, T., ... Stambouli, A. (2007). 82,000-year-old shell beads from North Africa and implications for the origins of modern human behavior. Proceedings of the National Academy of Sciences of the United States of America, 104(4), 9964-9969.

Chick, G. (1997). Cultural complexity: The concept and its measurement. Cross-Cultural Research, 31(4), 275-307.

Chrisomalis, S. (1996). Independent invention in anthropological context. Unpublished manuscript. https://www. academia. edu/5622705/independent_invention_in_anthropological_context

Coolidge, F. L., \& Overmann, K. A. (2012). Numerosity, abstraction, and the emergence of symbolic thinking. Current Anthropology, 53(2), 204-225.

d'Errico, F. (1991). Microscopic and statistical criteria for the identification of prehistoric systems of notation. Rock Art Research, 8, 83-93.

d'Errico, F., Henshilwood, C. S., Vanhaeren, M., \& Van Niekerk, K. L. (2005). Nassarius kraussianus shell beads from Blombos Cave: Evidence for symbolic behaviour in the Middle Stone Age. Journal of Human Evolution, 48(1), 3-24.

d'Errico, F., Vanhaeren, M., \& Wadley, L. (2008). Possible shell beads from the Middle Stone Age layers of Sibudu Cave, South Africa. Journal of Archaeological Science, 35, 2675-2685.

d'Errico, F., Vanhaeren, M., Barton, N., Bouzouggar, A., Mienis, H., Richter, D., ... Lozouet, P. (2009). Additional evidence on the use of personal ornaments in the Middle Paleolithic of North Africa. Proceedings of the National Academy of Sciences of the United States of America, 106(38), 16051-16056.

de Cruz, H. (2008). An extended mind perspective on natural number representation. Philosophical Psychology, 21(4), 475-490.

de Cruz, H. (2012). Are numbers special? Cognitive technologies, material culture and deliberate practice. Current Anthropology, 53(2), 204-225.

Dehaene, S. (2007). Symbols and quantities in parietal cortex: Elements of a mathematical theory of number representation and manipulation. In P. Haggard, Y. Rossetti, \& M. Kawato (Eds.), Sensorimotor foundations of higher cognition: Attention and performance (pp. 527-574). Oxford: Oxford University Press. 
Dehaene, S., \& Cohen, L. (2007). Cultural recycling of cortical maps. Neuron, 56(2), 384-398.

Denton, T. (2004). Cultural complexity revisited. Cross-Cultural Research, 38(1), 3-26.

Depew, D. J. (2003). Baldwin and his many effects. In B. Weber \& D. Depew (Eds.), Evolution and learning: The Baldwin effect reconsidered (pp. 3-32). Cambridge: MIT Press.

Divale, W. (1999). Climatic instability, food storage, and the development of numerical counting: A crosscultural study. Cross-Cultural Research, 33(4), 341-368.

Englund, R. K. (1988). Administrative timekeeping in ancient Mesopotamia. Journal of the Economic and Social History of the Orient, 31, 121-185.

Gibson, J. J. (1977). The theory of affordances. In Perceiving, acting, and knowing: Toward an ecological Psychology (pp. 127-143). Hillsdale: Lawrence Erlbaum.

Gibson, J. J. (1979). The ecological approach to visual perception. Boston: Houghton Mifflin.

Glassner, J.-J. (2000). The invention of cuneiform: Writing in Sumer. (Z. Bahrani, \& M. Van de Mieroop, trans.). Baltimore: Johns Hopkins University Press.

Güleç, E., Kuhn, S. L., \& Stiner, M. C. (2002). The early Upper Palaeolithic of Üçağızlı Cave, Turkey. Antiquity, 76(293), 615-616.

Haas, C. (1996). Writing technology: Studies on the materiality of literacy. New York: Routledge.

Hall, B. K. (2003). Baldwin and beyond: organic selection and genetic assimilation. In B. Weber \& D. Depew (Eds.), Evolution and learning: The Baldwin effect reconsidered (pp. 141-167). Cambridge: MIT Press.

Hayden, B. (2001). Fabulous feasts: A prolegomenon to the importance of feasting. In M. Dietler \& B. Hayden (Eds.), Feasts: Archaeological and ethnographic perspectives on food, politics, and power (pp. 23-64).Tuscaloosa: University of Alabama Press.

Hayden, B., \& Villeneuve, S. (2011). Astronomy in the Upper Palaeolithic? Cambridge Archaeological Journal, 21(3), 331-355.

Henshilwood, C., d’Errico, F., Vanhaeren, M., Van Niekerk, K., \& Jacobs, Z. (2004). Middle Stone Age shell beads from South Africa. Science, 34, 404.

Hodder, I. (2012). Entangled: An archaeology of the relationships between humans and things. Malden: Wiley-Blackwell.

Hutchins, E. (1995). Cognition in the wild. Cambridge: MIT Press.

Jègues-Wolkiewiez, C. (2005). Aux racines de l'astronomie, ou l'ordre caché d'une oeuvre paléolithique. Antiquités Nationales, 37, 43-62.

Jerardino, A., \& Marean, C. W. (2010). Shellfish gathering, marine paleoecology and modern human behavior: Perspectives from cave PP13B, Pinnacle Point, South Africa. Journal of Human Evolution, 59(3), 412-424.

Kendal, J., Tehrani, J. J., \& Odling-Smee, J. (2011). Human niche construction in interdisciplinary focus. Philosophical Transactions of the Royal Society of London, Series B, 366(1566), 785-792.

Kuhn, S. L., Stiner, M. C., Reese, D. S., \& Güleç, E. (2001). Ornaments of the earliest Upper Paleolithic: New insights from the Levant. Proceedings of the National Academy of Sciences of the United States of America, 98(13), 7641-7646.

Kuhn, S. L., Stiner, M. C., Güleç, E., Özer, I., Yılmaz, H., Baykara, I., ... Suata-Alpaslan, F. (2009). The early upper Paleolithic occupations at Üçağızlı cave (Hatay, Turkey). Journal of Human Evolution, 
56(2), 87-113.

Leroi-Gourhan, A. (1967). Les mains de Gargas: Essai pour une étude d'ensemble. Bulletin de la Société Préhistorique Française, 64(1), 107-122.

MacGinnis, J., Monroe, M. W., Wicke, D., \& Matney, T. (2014). Artefacts of cognition: The use of clay tokens in a Neo-Assyrian provincial administration. Cambridge Archaeological Journal, 24(2), 289-306.

Malafouris, L. (2010). Grasping the concept of number: How did the sapient mind move beyond approximation? In C. Renfrew \& I. Morley (Eds.), The archaeology of measurement: Comprehending heaven, earth and time in ancient societies (pp. 35-42). Cambridge: Cambridge University Press.

Malafouris, L. (2013). How things shape the mind: A theory of material engagement. Cambridge: MIT Press.

Marshack, A. (1991). The roots of civilization: The cognitive beginnings of man's first art, symbol and notation. Revised and expanded edition. New York: Moyer Bell Ltd.

McBrearty, S., \& Brooks, A. S. (2000). The revolution that wasn't: A new interpretation of the origin of modern human behavior. Journal of Human Evolution, 39(5), 453-563.

Murdock, G. P., \& Provost, C. (1973). Measurement of cultural complexity. Ethnology, 12(4), 379-392.

Nissen, H. J., Damerow, P, \& Englund, R. K. (1993). Archaic bookkeeping: Early writing and techniques of economic administration in the Ancient Near East. (P. Larsen, trans.). Chicago: University of Chicago Press.

Ochs, E., \& Capps, L. (2001). Living narrative: Creating lives in everyday storytelling. Cambridge: Harvard University Press.

Orban, G. A., Claeys, K., Nelissen, K., Smans, R., Sunaert, S., Todd, J. T., ... Vanduffel, W. (2006). Mapping the parietal cortex of human and non-human primates. Neuropsychologia, 44(13), 2647-2667.

Overmann, K. A. (2013a). Material scaffolds in numbers and time. Cambridge Archaeological Journal, 23(1), 19-39.

Overmann, K. A. (2013b). Numbers and time: A cross-cultural investigation of the origin and use of numbers as a cognitive technology. MA Thesis, University of Colorado, Colorado Springs.

Overmann, K. A. (2014). Finger-counting in the Upper Palaeolithic. Rock Art Research, 31(1), 63-80.

Renfrew, C., \& Malafouris, L. (2008). Steps to a "neuroarchaeology” of mind. Cambridge Archaeological Journal, 18(3), 381-385.

Rouillon, A. (2006). Au Gravettien, dans la grotte Cosquer (Marseille, Bouches-du-Rhône), l'Homme a-til compté sur ses doigts? Anthropologie, 110(4), 500-509.

Schmandt-Besserat, D. (1992a). Before writing: From counting to cuneiform (2 vols.). Austin: University of Texas Press.

Schmandt-Besserat, D. (1992b). How writing came about. Austin: University of Texas Press.

Schmandt-Besserat, D. (2001). Feasting in the ancient Near East. In M. Dietler \& B. Hayden (Eds.), Feasts: Archaeological and ethnographic perspectives on food, politics, and power (pp. 391-403). Tuscaloosa: University of Alabama Press.

Tallis, R. (2011). Aping mankind: Neuromania, Darwinitis and the misrepresentation of humanity. Durham: Acumen.

Tomasello, M., \& Herrmann, E. (2010). Ape and human cognition: What's the difference? Current 
Directions in Psychological Science, 19(1), 3-8.

Tomasello, M., Kruger, A. C., \& Ratner, H. H. (2010). Cultural learning. Behavioral and Brain Sciences, 16(3), 495-511.

Vanhaeren, M., d'Errico, F., Stringer, C., James, S. L., Todd, J. A., \& Mienis, H. K. (2006). Middle Paleolithic shell beads in Israel and Algeria. Science, New Series, 312(5781), 1785-1788.

Vanhaeren, M., d’Errico, F., Van Niekerk, K. L., Henshilwood, C. S., \& Erasmus, R. M. (2013). Thinking strings: Additional evidence for personal ornament use in the Middle Stone Age at Blombos Cave, South Africa. Journal of Human Evolution, 64(6), 500-517.

Waddington, C. H. (1942). Canalization of development and the inheritance of acquired characters. Nature, 150(3811), 563-565.

Wynn, T., Overmann, K. A., Coolidge, F. L., \& Janulis, K. (2017). Bootstrapping ordinal thinking. In T. Wynn \& F. L. Coolidge (Eds.), Cognitive models in Palaeolithic archaeology (pp. 197-213). Oxford: Oxford University Press.

Zilhão, J. (2007). The emergence of ornaments and art: An archaeological perspective on the origins of "behavioral modernity.” Journal of Archaeological Research, 15(1), 1-54. 